\title{
Iodine and Selenium Intake in a Sample of Women of Childbearing Age in Palmerston North, New Zealand after Mandatory Fortification of Bread with Iodised Salt
}

\author{
Nurul Husna Shukri ${ }^{1}$, Jane Coad², Janet Weber ${ }^{2}$, Ying Jin $^{2}$, Louise Brough ${ }^{2 *}$ \\ ${ }^{1}$ Department of Nutrition and Dietetics, Faculty of Medicine and Health Sciences, Universiti Putra Malaysia, Selangor, Malaysia; \\ ${ }^{2}$ Institute of Food, Nutrition and Human Health, Massey University, Palmerston North, New Zealand. \\ Email: 1 l.brough@massey.ac.nz
}

Received November $7^{\text {th }}$, 2013; revised December $7^{\text {th }}$, 2013; accepted December $14^{\text {th }}, 2013$

Copyright (C) 2014 Nurul Husna Shukri et al. This is an open access article distributed under the Creative Commons Attribution License, which permits unrestricted use, distribution, and reproduction in any medium, provided the original work is properly cited. In accordance of the Creative Commons Attribution License all Copyrights @ 2014 are reserved for SCIRP and the owner of the intellectual property Nurul Husna Shukri et al. All Copyright (C) 2014 are guarded by law and by SCIRP as a guardian.

\begin{abstract}
Iodine deficiency is a worldwide public health problem, which has long been observed in many parts of the world, including New Zealand (NZ). The aim of this study was to assess iodine and selenium intake among women of childbearing age in Palmerston North, New Zealand post mandatory fortification of bread with iodised salt. Fifty women of childbearing age completed a researcher-led questionnaire, including a semi-quantitative food frequency questionnaire. Iodine and selenium were analysed in 24-hour urine samples. The median urinary iodine concentration (UIC) was $65 \mu \mathrm{g} / \mathrm{l}$ with $30 \%$ below $50 \mu \mathrm{g} / \mathrm{l}$; representing mild iodine deficiency according to the World Health Organization. The estimated median daily iodine intake (130 $\mu \mathrm{g} / \mathrm{day})$ was higher than the Estimated Average Requirement (100 $\mu \mathrm{g} / \mathrm{day})$ and higher than seen in women prior to fortification. The median excretion of selenium ( $32 \mathrm{\mu g} / \mathrm{day})$ was slightly above level suggested as adequate ( $30 \mathrm{\mu g} / \mathrm{day})$ and estimated median intake (57 $\mathrm{\mu g} / \mathrm{day})$ was higher than Estimated Average Requirement (50 $\mathrm{\mu g} / \mathrm{day})$. Selenium and iodine excretion were significantly correlated (Spearman's rank order; $r(50)=0.547, p<0.001)$. The major contributors to iodine intake were milk (36\%), bread (25\%) and fish/seafood (15\%). Participants had a mean intake of 2.5 slices of bread/day, which contributed approximately 14 to $20 \mu \mathrm{g}$ of iodine. The majority of participants (74\%) had iodised salt at home, but less than half $(\mathbf{4 8 \%})$ used iodised salt exclusively. In conclusion, despite the mandatory fortification of bread with iodised salt in NZ, UIC of the study population indicates iodine deficiency although their estimated dietary intakes appear adequate. It is essential that government initiatives to improve iodine status are evaluated for their efficacy.
\end{abstract}

\section{KEYWORDS}

Iodine; Selenium; Iodine Intake; Iodine Fortification; Iodised Salt

\section{Introduction}

Iodine deficiency disorders (IDD) are a major worldwide public health problem, with approximately 1.88 billion people reported to have insufficient iodine intake in 2011 [1]. IDD is the largest cause of preventable brain damage in childhood [2]. Iodine is needed to synthesize thyroid hormones (thyroxine and triiodothyronine), which are crucial for metabolism and maintaining growth and men-

${ }^{*}$ Corresponding author. tal development [2]. Iodine deficiency (ID), characterised by endemic goitre and very low urinary iodine concentrations $(<50 \mu \mathrm{g} / \mathrm{l})$, was prevalent in New Zealand (NZ) in the late 1800s and early 1900s [3,4]. The main cause of ID in NZ is low iodine levels in the soil and hence the food supply. The NZ government introduced iodisation of salt in the 1924 at the level of $<40 \mathrm{mg} / \mathrm{kg}$; this was increased to 40 - $80 \mathrm{mg} / \mathrm{kg}$ in 1938 [4]. Goitre was eradicated in the 1950s and ID appeared to be eliminated in the 1970s [5,6]. However, since the 1990s, many studies 
New Zealand after Mandatory Fortification of Bread with Iodised Salt

in NZ have demonstrated mild-to-moderate ID among children and adults, including pregnant and lactating women and their infants [3]; with urinary iodine concentrations (UIC) below recommendations [7].

Severe ID during pregnancy or infancy can result in adverse consequences for both mothers and their infants, such as maternal hypothyroidism, cretinism, physical deformity and mental retardation [8]. Whereas, mild to moderate ID during pregnancy and lactation may have a more subtle damaging effect on psychological development and cognitive functions in infants [8]. Two recent studies in developed countries have demonstrated that even mild to moderate iodine deficiency during pregnancy, can have cognitive effects. A cohort study of 958 pregnant women in the UK found an association between inadequate iodine status during pregnancy and an adverse risk on child cognitive development in their children at 8 and 9 years old as maternal iodine status decreased during early pregnancy, the risk of suboptimum IQ scores increased in childhood [9]. Similarly, a study of 228 children in Tasmania, Australia showed that children of mothers with mild ID in pregnancy had poorer educational outcome, with reduced scores in spelling, grammar and English literacy, at age nine years compared to children of iodine-replete mothers [10].

In September 2009, Food Standards Australian New Zealand implemented the mandatory addition of iodised salt (25 to $65 \mathrm{mg} / \mathrm{kg}$ ) to all bread (except organic, parbaked and unleavened bread) [11]. This policy was predicted to improve the iodine intake for the majority of the population [12]. However, iodine requirements increase substantially during pregnancy and lactation and the fortification will be insufficient for pregnant and lactating women to meet recommendations; hence in July 2010, a subsidised supplement containing $150 \mu$ g iodine (as potassium iodide) was made available to all pregnant and lactating women [13].

There are also low levels of selenium in the NZ soil, thus the population is at risk of selenium insufficiency $[14,15]$. The main role for selenium is as an essential cofactor for glutathione peroxidase, a potent antioxidant. However, it also plays an important role in maintaining optimal function of the thyroid gland as it is involved in thyroid metabolism. In particular, the selenoproteins (iodothyronine deiodinases) are involved in the deiodination of thyroxine. Thus selenium deficiency may exacerbate the effect of ID and contribute to the accumulation of hydrogen peroxide in the thyroid gland [16]. Selenium has not been added to salt or bread in NZ.

The main objective of this study is to investigate iodine intake and status among a sample of women of childbearing age in Palmerston North, NZ post mandatory fortification of bread with iodised salt. A secondary objective of this study was to assess selenium intake to determine any association between these two nutrients.

\section{Methods}

\subsection{Participants and Recruitment}

Fifty healthy women, aged 18 to 40 years were recruited from the Palmerston North area via advertisements at local health care, sports and community centres and tertiary institutions. Women were recruited from June 2010 to August 2010, which is about 9 to 11 months postmandatory iodine fortification. Women were excluded if they were pregnant or breastfeeding, or had thyroid disease or were taking medication containing iodine and/or selenium.

\subsection{Data Collection}

All participants visited the Human Nutrition Research Unit (HNRU) at Massey University in Palmerston North and completed a researcher led questionnaire including questions about iodised salt usage, intake of supplements containing iodine and/or selenium, and awareness of iodine fortification in NZ, that was based on a previous study of pregnant and breastfeeding women [17]. The questionnaire also included an iodine-specific semi-quantitative food frequency questionnaire (FFQ) that comprised of 14 food items; including intake of organic, par-baked bread and home-made bread, in order to determine the intake of bread containing non-iodised salt (breads exempt from mandatory iodine fortification). The frequency categories ranged from never, less than one per month, 1 - 3 times per month, once a week and every day, to more than once per day. The FFQ was only based on the main food sources of iodine in NZ, and it did not include the use of iodised salt or foods containing iodine at low levels. Therefore, the FFQ was not used to estimate the iodine intake of the study population. This FFQ is mainly used to identify the major contributor of food to iodine intake.

During the interview, participants described portion size and frequency of intake for each food item using photos from a food atlas [18]. Household food measurements, such as cups and plates were used to demonstrate the actual size of servings. The questionnaires used in the study had been pretested among Massey University women staff.

The participants were asked to collect a 24-hour urine sample and provided with an insulated box containing two polythene bottles for urine storage and frozen silica pads to keep the sample cool. All participants were also given verbal and written instructions regarding the collection of 24-hour urine samples. Reminders by email and/or messages by mobile phone were sent to partici- 
pants to ensure they collected all urine over 24 hours. All urine samples were brought immediately to the HNRU laboratory for processing after collection. The total volume of urine collected over 24 hours was measured for each participant. Samples were stored at -20 degrees C prior to analysis. Iodine and selenium concentrations in urine were determined by an accredited commercial laboratory (Hill Laboratories, Hamilton, New Zealand), using inductively-coupled plasma mass spectrometry [19]. Quality Control procedures included analysis of blanks, analytical repeats and spiked samples to ensure accuracy and precision (data not available). Calibration standards and checks were undertaken on every run and the limit of detection was $0.001 \mathrm{mg} / \mathrm{kg}$ and $0.002 \mathrm{mg} / \mathrm{kg}$ for iodine and selenium respectively.

Urinary iodine concentration is an effective biomarker for iodine status and it also reflects recent iodine intake [20]. The WHO, ICCIDD and UNICEF accepts the single 24-hour urine collection method for estimating the iodine status and intake of a population [21]. A 24-hour urine sample can be used to measure iodine and selenium intake as a constant amount is excreted in urine $(90 \%$ and $50 \%$ of dietary intake respectively).

\subsection{Data Analysis}

Data were analysed using the IBM SPSS Package Version 17 for Windows. Normality was tested for the continuous variables using the Shapiro-Wilks statistical analysis. Spearman's rank order correlation was used to describe the relationship between non-parametric data. UIC values were not normally distributed, so the median UIC of a study sample $(\mu \mathrm{g} / \mathrm{L})$ is used as an indicator for the iodine status of the population [7]. The 24-hour urinary iodine and selenium excretion ( $\mu \mathrm{g} /$ day) reflects individual intake the previous day. To estimate the change in contribution of iodine due to mandatory fortification, the iodine content in bread, prior- and post-fortification was calculated based on the formula adapted from Rose et al. (2009) [22] as shown below:

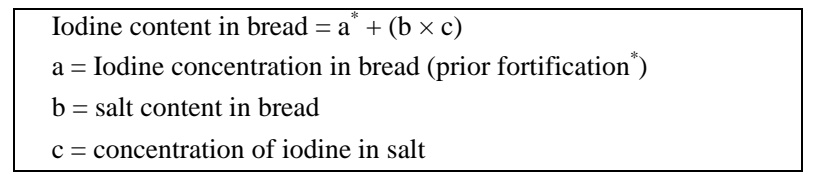

*Based on the previous iodine and salt content, sources from [23].

\subsection{Ethical Approval}

This study was approved by the Massey University Human Ethics Committee (Application 10/03). All participants provided written, informed consent.

\section{Results}

Fifty women of childbearing-age, who were not pregnant or breastfeeding, were recruited from the Palmerston North area. The majority of participants were aged between 18 to 34 years old (88\%) and were educated to tertiary level or above (90\%). Only two participants consumed supplements containing iodine (Table 1).

The median UIC of the study population was $65 \mu \mathrm{g} / \mathrm{l}$ (Table 2) which defined the population as being mildly iodine deficient (UIC range of 50 to $99 \mu \mathrm{g} / \mathrm{l}$ ) [7]. Additionally, 30\% of participants had a UIC below $50 \mu \mathrm{g} / \mathrm{l}$, and WHO/ICCIDD/UNICEF defines a population as iodine deficient if more than $20 \%$ has a UIC below 50 $\mu \mathrm{g} / \mathrm{l}$. Based on 24-hour urinary iodine excretion (UIE), the median estimated iodine intake was $130 \mu \mathrm{g} / \mathrm{day}$, greater than the Estimated Average Requirement (EAR) for women (100 $\mu \mathrm{g} /$ day).

Table 1. Sociodemographic characteristics, smoking status and use of salt and supplements $(n=50)$.

\begin{tabular}{|c|c|c|}
\hline Category & $\mathrm{n}$ & Percentage (\%) \\
\hline \multicolumn{3}{|l|}{ Age groups } \\
\hline $18-24$ & 21 & 42 \\
\hline $25-34$ & 23 & 46 \\
\hline $35-40$ & 6 & 12 \\
\hline \multicolumn{3}{|l|}{ Ethnicity } \\
\hline NZ European & 21 & 42 \\
\hline Maori & 8 & 16 \\
\hline Others: Asian, American, African, etc. & 21 & 42 \\
\hline \multicolumn{3}{|c|}{ Highest educational qualification } \\
\hline School/bursary & 2 & 4 \\
\hline Certificate & 3 & 6 \\
\hline Tertiary levels (university qualifications) & 45 & 90 \\
\hline \multicolumn{3}{|l|}{ Smoking status } \\
\hline Smoker & 1 & 2 \\
\hline Non-smokers & 49 & 98 \\
\hline Exposure to second-hand smoke & 7 & 14 \\
\hline \multicolumn{3}{|l|}{ Salt usage } \\
\hline Iodised salt only & 24 & 48 \\
\hline Iodised salt and non-iodised salt & 13 & 26 \\
\hline Non-iodised salt only & 13 & 26 \\
\hline \multicolumn{3}{|l|}{ Supplement intake } \\
\hline Multiple micronutrient containing iodine & 1 & 2 \\
\hline Sea kelp (containing iodine) & 1 & 2 \\
\hline Supplement containing selenium & 0 & 0 \\
\hline
\end{tabular}


Table 2. Urinary excretion and estimated daily intake of iodine and selenium $(n=50)$.

\begin{tabular}{ccc}
\hline \multirow{2}{*}{ Measurements/Categories } & \multicolumn{2}{c}{ Median $\left(25^{\text {th }}, 75^{\text {th }}\right.$ centile $)$} \\
\cline { 2 - 3 } & Iodine & Selenium \\
\hline Urinary concentration $(\mu \mathrm{g} / \mathrm{l})$ & $65(43.8,97.1)$ & $20(12.2,27)$ \\
Urinary excretion $(\mu \mathrm{g} / \mathrm{day})$ & $117(73.9,176.7)$ & $32(22.4,42.3)$ \\
Estimated daily intake $(\mu \mathrm{g} / \mathrm{day})^{\dagger}$ & $130(82.1,196.3)$ & $57(40.7,76.8)$ \\
\hline
\end{tabular}

${ }^{\dagger}$ Based on 24-hour urine excretion.

Median selenium urine excretion was $32 \mu \mathrm{g} /$ day, and the estimated selenium intake was $57 \mu$ g/day; above both the EAR (50 $\mu \mathrm{g} /$ day) and the lower limits of the safe range for intake (30 $\mu \mathrm{g} /$ day) [14,24].

Selenium excreted over 24 hours was significantly correlated with iodine excreted over 24 hours (Spearman's rank order; $r(50)=0.547, p<0.001)$. This is consistent with a significant correlation between selenium urinary concentration and urinary iodine concentration (Spearman's rank order; $r(50)=0.68, p<0.001$ ).

Milk was the main food source of iodine for the participants, contributing approximately $36 \%$ of overall dietary intake, followed by bread (25\%), fish and seafood (15\%), and eggs (14\%). Other food (such as yogurt, sushi and cheese) contributed less than 5\% each (Table 3). There was no correlation between UIC levels ( $\mu \mathrm{g} /$ day) and reported dietary intake of any food, including the estimated total iodine intake from the FFQ.

Based on the FFQ, the participants' average intake of bread post-fortification was only 2.5 medium size slices per day, which contributed approximately 14 to $20 \mu \mathrm{g}$ of iodine. For bread, the three highest contributors to iodine intake were wholemeal/wholegrain bread (59\%), white bread (14\%), muffins (13\%) and white roll (6\%); other types of bread (such as flat breads, bagel, etc) contributed 8\% (Table 3). Organic, par-baked and home-made breads (breads that are exempt from mandatory iodine fortification) were consumed at least twice per week by $8 \%, 12 \%$ and $30 \%$ of participants respectively. Using participant's dietary intake, it was estimated that their bread intake would contribute about $7.6 \%$ of total dietary iodine intakes if based on iodine content in bread prior to fortification. However, based on the iodine content post-fortification, this percentage increased to $25 \%$ using the calculation from Rose et al. (2009) [22]. Selenium content in bread was not calculated as the values were highly variable.

Only $4 \%$ of participants knew that the addition of iodised salt to bread is now mandatory in NZ, whereas more than half (56\%) reported not to have heard anything about iodine fortification, the remainder (14\%) indicated they were not sure whether it was mandatory or volun-
Table 3. Percentage contribution of foods to dietary iodine intake, based on estimated iodine intake from FFQ.

\begin{tabular}{cc}
\hline Food items & $\begin{array}{c}\text { Percentage contribution to overall } \\
\text { iodine intake (\%) }\end{array}$ \\
\hline Milk (all type) & 36 \\
Bread & 25 \\
Fish \& seafood & 15 \\
Egg & 14 \\
Sushi & 5 \\
Yoghurt & 4 \\
Cheese & 1 \\
Soy milk \& seameal custard & $<1$ \\
Types of bread & Percentage contribution to iodine \\
Wholemeal/wholegrain & 59 \\
White & 14 \\
Muffin & 13 \\
White roll & 6 bred consumption (\%) \\
Flat bread & 4 \\
Bagels & 3 \\
\hline Bannock/crumpet/croissant & \\
\hline
\end{tabular}

tary. In contrast, almost half of the participants (46\%) knew that voluntary fortification of bread with folic acid was permitted in NZ. Although many of participants had iodised salt at home (74\%), only $48 \%$ used iodised salt exclusively (Table 1). Other salts used by participants included plain salt (26\%), mineral salt (such as sea salt or rock salt) (36\%) and herb salt (6\%), however 26\% had no iodised salt at home.

\section{Discussion}

After the mandatory fortification of bread with iodine in $\mathrm{NZ}$, the present study population is defined as mildly iodine deficient according to the WHO cut-off point (50 $99 \mu \mathrm{g} / \mathrm{l})$. However, Zimmerman and Anderson (2012) [25] advocate that the WHO cut-off point for adults may be too high, and suggest it should be $60-70 \mu \mathrm{g} / \mathrm{l}$. The median UIC of study population $(65 \mu \mathrm{g} / \mathrm{l})$ is within this range, suggesting mild iodine deficiency among the study population.

Previous studies in NZ since the 1990s, prior to mandatory fortification, showed women had mild to moderate ID with median UIC between 40 to $55 \mu \mathrm{g} / \mathrm{l}$ [3,15, 26]. Although there is no comparative data prior to fortification from Palmerston North, the present study dem- 
onstrated a higher median UIC than previous NZ studies, suggesting a small increase in iodine status; most likely due to fortified bread. It is unlikely the increase is due to differences in methods, many of the previous studies used only a spot urine sample, however the present study used a 24-hour urine sample, which is a better indicator as it is not influenced by the variation time of day and less likely to be influenced by hydration status [7].

Based on 24-hour UIE, the estimated median iodine intake (130 $\mu \mathrm{g} /$ day) was above the EAR (100 $\mu \mathrm{g} /$ day $)$, suggesting an adequate iodine intake for this population, this is contrary to the WHO definition. Zimmerman and Andersson (2012) [25] suggest the use of the EAR cutpoint method which comprises comparing the estimated intake of the population with the EAR. This method requires the collection of multiple urine samples in a subset to adjust for intra-individual variation; this together with the small sample size mean the EAR cut-point method cannot be applied to the current results. However, another possible interpretation of the discrepancy in the current study results is that the study population had a sufficient intake. Further research is required using the EAR cut-point method to determine whether intakes are adequate. Inadequate iodine status was recently reported among breastfeeding women in NZ and Australia postfortification, especially among women who did not consume the recommended iodine supplements $[17,27]$. In $\mathrm{NZ}$, a study of a small sample of pregnant and lactating mothers before (2009) and after (2011) iodine fortification, found that the median UIC was higher in 2011 compared with 2009 for both pregnant (85 and $47 \mathrm{mg} / \mathrm{L}$ ) and lactating (74 and $34 \mathrm{mg} / \mathrm{L}$ ) women [17]. However, the study population's median UICs post-fortification were still below the cut-offs for adequate iodine status [17]. Another post-fortification study in NZ among school-aged children also found that although intakes had increased, serum thyroglobulin concentrations indicated mild deficiency [28]. This suggests that iodine fortification of bread may help to increase iodine intake and reduce the risk of ID, but may not fully eliminate ID in NZ.

The mean iodine intake of women in NZ (aged 16 - 44 year) was projected to increase by approximately $73 \mu \mathrm{g} /$ day, after mandatory iodine fortification [6]. However, UIC in the current study $(65 \mu \mathrm{g} / \mathrm{l})$ represents an increment of only $25 \%$ (13 $\mu \mathrm{g} /$ day) compared to the median UIC $(52 \mu \mathrm{g} / \mathrm{l})$ of women in a national study prior to iodine fortification [26]. Although, the estimated iodine intake $(130 \mu \mathrm{g} /$ day $)$ in the present study was twice the intake estimated for women prior to fortification (63 $\mu \mathrm{g}$ /day) in the 2009 New Zealand Total Diet Survey (NZTDS) [29], their urinary iodine status still classified them as iodine-deficient. In addition, the estimated median intake is below the EAR of 160 and $190 \mu \mathrm{g} /$ day for pregnant and lactating women respectively, thus they would remain at risk of inadequate iodine intake if they became pregnant, despite mandatory fortification. Higher levels of iodine could not be added to bread since this could result in children, who have a high consumption of bread, relative to their size, exceeding the upper level of intake. It is therefore essential that pregnant and lactating women use the subsidised iodine supplement to ensure sufficient iodine intake during this time. However, a recent observational study in NZ $(n=723)$ reported low use of iodine containing supplements among pregnant women, especially low income women [29].

Based on the FFQ, dairy food is the major contributor to iodine intake in the study population, similar to the dietary intake pattern reported in the 2003/04 and 2009 NZTDS [30]. The 2008/09 NZ Adult Nutrition Survey reported that the majority (84.2\%) of NZ population aged 15 and above use iodised salt at home [26], however the exclusive use of iodised salt was not reported and could be much lower. A previous NZ study found $93 \%$ have iodised salt at home, however $30 \%$ of them never use iodised salt in cooking and less than half (48\%) never use iodised salt as table salt [31]. In the present study, although majority of participants (74\%) had iodised salt at home, less than half $(48 \%)$ used it exclusively while the remainder (52\%) use it rarely or never.

Healthy eating guidelines recommend that only iodised salt should be used in cooking or added to meals [32], however, in the current study less than half of the study population adhered to this advice, preferring to use alternative salts. Public health recommendations to reduce sodium intake and an increase trend of using mineral salts in NZ may have reduced the usage of iodised salt in cooking or as table salt [6]. Other changes in eating habits may have contributed to the reduction of iodine intakes; for example people tend to eat away from home or buy more takeaway meals, and/or eat more processed foods, which generally contain non-iodised salt $[5,6]$.

Habitual intake of unfortified bread is also a challenge to the government's current strategy to increase iodine intake. This is because, iodine-fortified bread is not consumed by all people; some might make their own bread using non-iodised salt, purchase organic bread, or totally avoid bread, due to e.g. medical reasons (coeliac disease), religious beliefs or cultural reasons, and/or a food preferences [33]. These may have contributed to the smaller than predicted increase in UIC among the present study population. Of interest is the fact that the majority of participants were more aware of the situation regarding folic acid than iodine fortification of bread, although the mandatory addition of both nutrients was due to be carried out simultaneously in NZ; although in NZ the legislation for mandatory fortification with folate was rejected, 
so folate fortification remains voluntary.

Median estimated selenium intakes were slightly above the level suggested to be adequate ( $30 \mu \mathrm{g} /$ day) [14], however some women were estimated to have very low intakes based on 24-hour urine excretion. In the current study, iodine and selenium status were found to be moderately, positively correlated. A previous NZ study found no association between selenium plasma and thyroid status and the authors suggest that low selenium status did not significantly affect people with marginal iodine status [34]. However the present population study has been categorised as having mild ID, so adverse effects from concurrent low selenium and iodine cannot be ruled out [35]. Rasmussen et al. (2011) found that low selenium status among women living in areas of mild ID is associated with an increased risk of thyroid enlargement and increased susceptibility to multiple nodule formation [35]. Although their study demonstrated a weak association, they suggested that optimal selenium status may help to prevent IDD, particularly goitre [35]. The minimal requirement of selenium in order to optimise the function of iodothyronine deiodinases enzymes and glutathione peroxidase is approximately $30 \mu \mathrm{g} /$ day and 45 $\mu \mathrm{g} /$ day, respectively [14]. WHO, FAO and IAEA [24] and Thomson (2004) [14], asserts the requirement of at least $30 \mu \mathrm{g} /$ day is adequate to satisfy the optimal function of selenoproteins and does not appear to cause any adverse health consequences in NZ; thus 25 - $40 \mu \mathrm{g} / \mathrm{day}$ of selenium is suggested to be sufficient.

Blood selenium concentration has been accepted as a useful biomarker of selenium status and intake and is the most widely used method in research [36]. However, both dietary intake and plasma selenium have been associated with daily urinary excretion especially in populations that live in selenium-deficient areas and urine can be used to assess recent selenium intake [20]. The authors acknowledge the limitation of not measuring plasma selenium, however, the measurement of selenium in 24 hour urine samples serves as a proxy measure for selenium intake in a population and indicates the need for further research.

The findings of this pilot study cannot be generalised for the whole population in NZ, since the sample is relatively homogenous, due to the recruitment of only women living in Palmerston North. The recruitment was also more active in the university area compared to other locations in Palmerston North, which resulted in a predominance of highly educated women amongst the participants. Therefore, further research is required of a larger sample of women throughout NZ including ethnic minority and low income populations.

\section{Conclusion}

Despite initiatives, UIC of the study population indicates mild iodine deficiency although their estimated dietary intakes are higher than in those in women of childbearing age prior to fortification. This is most likely due to the mandatory fortification of bread with iodised salt, but the increase was not as large as anticipated. However, ID remains; and it would be especially difficult for pregnant or lactating women to achieve recommendations from dietary sources alone. Some women may have very low selenium intakes and deficiency may exacerbate ID. Evaluation of the effectiveness of government initiatives to improve iodine intake throughout the population is essential, especially amongst pregnant and lactating women and their infants. This is vital to optimise thyroid function and cognitive performance, growth and development in infancy.

\section{Acknowledgements}

We wish to thank to all participants, Mrs Chris Booth for help in the Human Nutrition Research Unit and Fliss Jackson for help with samples. This study was supported by a grant from Institute of Food, Nutrition \& Human Health, Massey University, NZ and an MSc scholarship for Nurul Husna from the Malaysia Ministry of Higher Education. The authors have no conflicts of interest.

\section{REFERENCES}

[1] M. Andersson, V. Karumbunathan and M. B. Zimmermann, "Global Iodine Status in 2011 and Trends over the Past Decade,” Journal of Nutrition, Vol. 142, No. 4, 2012, pp. 744-750. http://dx.doi.org/10.3945/jn.111.149393

[2] M. B. Zimmermann, P. L. Jooste and C. S. Pandav, “Iodine-Deficiency Disorders,” Lancet, Vol. 372, No. 9645, 2008, pp. 1251-1262. http://dx.doi.org/10.1016/S0140-6736(08)61005-3

[3] C. D. Thomson and S. Skeaff, "Chapter 129-Iodine Status and Deficiency Disorders in New Zealand,” In: R. P. Victor, N. B. Gerard and W. Ronald, Eds., Comprehensive Handbook of Iodine, Academic Press, San Diego, 2009, pp. 1251-1258.

http://dx.doi.org/10.1016/B978-0-12-374135-6.00129-1

[4] H. D. Purves, "The Aetiology and Prophylaxis of Endemic Goitre and Cretinism. The New Zealand Experience," The New Zealand Medical Journal, Vol. 80, 1974, pp. 477-479.

[5] J. Mann and E. Aitken, "The Re-Emergence of Iodine Deficiency in New Zealand?” The New Zealand Medical Journal, Vol. 116, No. 1170, 2003, pp. 351-355.

[6] C. Thoma, J. Seal, D. Mackerras and A. Hunt, "Chapter 26-Iodine Fortification of Bread: Experiences from Australia and New Zealand,” In: P. Victor, W. Ronald and P. Vinood, Eds., Flour and Breads and their Fortification in Health and Disease Prevention, Academic Press, San Diego, 2011, pp. 281-291.

http://dx.doi.org/10.1016/B978-0-12-380886-8.10026-1 
[7] WHO, UNICEF and ICCIDD, “Assessment of Iodine Deficiency Disorders and Monitoring Their Elimination. A Guide for Programme Managers,” World Health Organization, Geneva, 2007.

[8] M. B. Zimmermann, "Iodine Deficiency in Pregnancy and the Effects of Maternal Iodine Supplementation on the Offspring: A Review,” The American Journal of Clinical Nutrition, Vol. 89, No. 2, 2009, pp. 668S-672S. http://dx.doi.org/10.3945/ajcn.2008.26811C

[9] S. C. Bath, C. D. Steer, J. Golding, P. Emmet and M. P. Rayman, "Effect of Inadequate Iodine Status in UK Pregnant Women on Cognitive Outcomes in Their Children: Results from the Avon Longitudinal Study of Parents and Children (ALSPAC),” Lancet, Vol. 382, No. 9889, 2013, pp. 331-337. http://dx.doi.org/10.1016/S0140-6736(13)60436-5

[10] K. L. Hynes, C. L. Blizzard, P. Otahal, A. J. Venn, J. A. Seal, R. Taylor, et al., "Mild Iodine Deficiency during Pregnancy Is Associated with Reduced Educational Outcomes in the Offspring: 9-Year Follow-Up of the Gestational Iodine Cohort,” Journal of Clinical Endocrinology \& Metabolism, Vol. 98, No. 5, 2013, pp. 1954-1962. http://dx.doi.org/10.1210/jc.2012-4249

[11] Food Standards Australia NZ. Food Standards Code, “Standard 2.1.1. Cereals and Cereal Products," 2009. http://www.comlaw.gov.au/Details/F2009C00811

[12] S. Schiess, P. J. Cressey and B. M. Thomson, "Predictive Modelling of Interventions to Improve Iodine Intake in New Zealand,” Public Health Nutrition, Vol. 15, No. 10, 2012, pp. 1932-1940. http://dx.doi.org/10.1017/S1368980011003545

[13] Ministry of Health New Zealand, "Supplement (Tablet) to Take When Pregnant or Breastfeeding,” 2010. www.health.govt.nz/our-work/life-stages/maternity-servic es/supplement-tablet-take-when-pregnant-or-breastfeeding

[14] C. D. Thomson, "Assessment of Requirements for Selenium and Adequacy of Selenium Status: A Review,” European Journal of Clinical Nutrition, Vol. 58, 2004, pp. 391-402. http://dx.doi.org/10.1038/sj.ejcn.1601800

[15] C. D. Thomson, "Selenium and Iodine Intakes and Status in New Zealand and Australia," British Journal of Nutrition, Vol. 91, No. 5, 2004, pp. 661-672. http://dx.doi.org/10.1079/BJN20041110

[16] V. Triggiani, E. Tafaro, V. A. Giagulli, C. Sabba, F. Resta, B. Licchelli, et al., "Role of Iodine, Selenium and Other Micronutrients in Thyroid Function and Disorders," Endocrine, Metabolic \& Immune Disorders-Drug Targets, Vol. 9, No. 3, 2009, pp. 277-294. http://dx.doi.org/10.2174/187153009789044392

[17] L. Brough, Y. Jin, N. H. Shukri, Z. R. Wharemate, J. L Weber and J. Coad, "Iodine Intake and Status during Pregnancy and Lactation before and after Government Initiatives to Improve Iodine Status, in Palmerston North, New Zealand: A Pilot Study,” Maternal \& Child Nutrition, 2013. http://dx.doi.org/10.1111/mcn.12055

[18] M. Nelson, M. Atkinson and J. Meyer, "Food Portion Size: A User's Guide to the Photographic Atlas,” Minis- try of Agriculture Fisheries and Food, London, 1997.

[19] P. A. Fecher, I. Goldmann and A. Nagengast, "Determination of Iodine in Food Samples by Inductively Coupled Plasma Mass Spectrometry after Alkaline Extraction,” Journal of Analytical Atomic Spectrometry, Vol. 13, No. 9, 1998, pp. 977-982. http://dx.doi.org/10.1039/a801671b

[20] R. S. Gibson, “Assessment of Iodine and Selenium Status,” In: R. S. Gibson, Ed., Principles of Nutritional Assessment, 2nd Edition, Oxford University Press, New York, 2005, pp. 750-766.

[21] WHO, ICCIDD and UNICEF, "Progress towards the Elimination of Iodine Deficiency Disorders,” World Health Organization, Geneva, 1999.

[22] M. Rose, R. Gordon and S. Skeaff, "Using Bread as a Vehicle to Improve the Iodine Status of New Zealand Children,” The New Zealand Medical Journal, Vol. 122, No. 1290, 2009, pp. 14-23.

[23] The New Zealand Institute for Crop \& Food Research, "FOODfiles," Crop \& Food Research, Christchurch, 2006.

[24] WHO and FAO, "Vitamin and Mineral Requirements in Human Nutrition: Selenium,” World Health Organization, Geneva, 2004.

[25] M. B. Zimmermann and M. Andersson, "Assessment of Iodine Nutrition in Populations: Past, Present, and Future,” Nutrition Reviews, Vol. 70, No. 10, 2012, pp. 553-570. http://dx.doi.org/10.1111/j.1753-4887.2012.00528.x

[26] University of Otago, MOH, “A Focus on Nutrition, Key Findings of the 2008/09 New Zealand Adult Nutrition Survey,” Ministry of Health NZ, Wellington, 2011. http://www.health.govt.nz/publication/focus-nutrition-key -findings-2008-09-nz-adult-nutrition-survey

[27] L. B. Rasmussen, L. Ovesen, I. Bulow, T. Jorgensen, N. Knudsen, P. Laurberg, et al., "Evaluation of a SemiQuantitative Food Frequency Questionnaire to Estimate Iodine Intake," European Journal of Clinical Nutrition, Vol. 55, No. 4, 2001, pp. 287-292. http://dx.doi.org/10.1038/sj.ejcn.1601156

[28] S. A. Skeaff and E. Lonsdale-Cooper, "Mandatory Fortification of Bread with Iodised Salt Modestly Improves Iodine Status in Schoolchildren," British Journal of $\mathrm{Nu}$ trition, Vol. 109, No. 6, 2013, pp. 1109-1113. http://dx.doi.org/10.1017/S0007114512003236

[29] S. R. Mallard and L. A. Houghton, "Public Health Policy to Redress Iodine Insufficiency in Pregnant Women May Widen Sociodemographic Disparities,” Public Health Nutrition, 2013, pp. 1-9. http://dx.doi.org/10.1017/S1368980013001626

[30] R. Vannoort and B. Thomson, "2009 New Zealand Total Diet Survey: Agricultural Compound Residues, Selected Contaminant and Nutrient Elements,” Ministry of Agriculture and Forestry NZ, Wellington, 2011.

[31] C. D. Thomson, A. J Colls, J. V. Conaglen, M. Macormack, M. Stiles and J. Mann, "Iodine Status of New Zealand Residents as Assessed by Urinary Iodide Excretion and Thyroid Hormones," British Journal of Nutrition, Vol. 78, No. 6, 1997, pp. 901-912. 
http://dx.doi.org/10.1079/BJN19970208

[32] $\mathrm{MOH}$, "Eating for Healthy Adult New Zealanders/Te Kai Totika mo te Hunga Pakeke o Aotearoa. Breads and Cereal,” Ministry of Health NZ, Wellington, 2010.

[33] K. L. Hynes, C. L. Blizzard, P. Otahal, A. J. Venn, J. A. Seal, R. Taylor, et al., "Chapter 128-History of Iodine Deficiency in Schoolchildren in Tasmania, Australia,” In: R. P. Victor, N. B. Gerard and W. Ronald, Eds., Comprehensive Handbook of Iodine, Academic Press, San Diego, 2009, pp. 1233-1249. http://dx.doi.org/10.1016/B978-0-12-374135-6.00128-X

[34] C. D. Thomson, S. K. McLachlan, A. M. Grant, E. Paterson and A. J. Lillico, "The Effect of Selenium on Thyroid Status in a Population with Marginal Selenium and Iodine
Status,” British Journal of Nutrition, Vol. 94, No. 6, 2005, pp. 962-968. http://dx.doi.org/10.1079/BJN20051564

[35] L. B. Rasmussen, L. Schomburg, J. Kohrle, I. B. Pedersen, B. Hollenbach, A. Hög, et al., "Selenium Status, Thyroid Volume, and Multiple Nodule Formation in an Area with Mild Iodine Deficiency," European Journal of Endocrinology, Vol. 164, 2011, pp. 585-590. http://dx.doi.org/10.1530/EJE-10-1026

[36] K. Ashton, L. Hooper, L. J. Harvey, R. Hurst, A. Casgrain and S. J. Fairweather-Tait, "Methods of Assessment of Selenium Status in Humans: A Systematic Review," The American Journal of Clinical Nutrition, Vol. 89, No. 6, 2009, pp. 2025S-2039S. http://dx.doi.org/10.3945/ajcn.2009.27230F

\section{Abbreviations}

EAR: Estimate Average Requirement FFQ: Food Frequency Questionnaire ID: Iodine Deficiency IDD: Iodine Deficiency Disorder
HNRU: Human Nutrition Research Unit

NZTDS: New Zealand Total Diet Survey

UIC: Urinary Iodine Concentration

UIE: Urinary Iodine Excretion 